\begin{tabular}{|c|c|c|}
\hline & $\begin{array}{l}\text { ANNALES INSTITUTI SLAVICI } \\
\text { UNIVERSITATIS DEBRECENIENSIS }\end{array}$ & \\
\hline SLAVICA XLVIII & 2019 & DEBRECEN \\
\hline
\end{tabular}

Ольга Сюч - Дина ТАНАТОВА - Татьяна ЮдинА

\title{
КУЛЬТУРА В ЦИФРОВОМ ФОРМАТЕ
}

\section{Culture in Digital Format}

\begin{abstract}
The article analyzes the changes in traditional culture triggered by technologies and development of its new formats as a result, such as clip culture, screen culture, culture of computer games, etc. It touches upon the influence on culture of the personal computer and other numerous digital devices, in particular the Internet, artificial intelligence, computer graphics, and virtual reality. Traditional means of communication (books, photographs, audio and video recordings, digital TV, etc.) that are most influenced by digital technologies are also discussed.

As traditional culture is losing its original features that emphasize the difference between different peoples, societies and their individual characteristics, all these processes are extensive, generating not only progressive, but negative trends.

On the one hand modern culture has become accessible to everybody, on the other hand, it has lost the «romance» of personal communication. The article points out that nowadays the investigation of culture in digital format does not primarily mean analyzing its phenomena and artifacts in themselves. It is rather a matter of monitoring further transformations and contributing the unique features of traditional culture preservation, without diminishing the importance of digital technologies as a whole in society.
\end{abstract}

Keywords: traditional and modern culture; digitalization, digital format, virtuality, artificial intelligence

Цифровизация культуры появилась несколько десятилетий назад, однако все ее возможности раскрылись только сейчас, благодаря процессам масштабной цифровизации практически всех сфер общества [ТАНАТОВА 2019; ЮдИНА 2019]. Прогрессирующая цифровизация мировой культуры: от массового включения человека в социальные сети, микроблоги и интерактивные видеоигры с их комфортным дубликатом реальности, гиперреальной (в том числе и в формате 3D) кино- и медиаэстетики, до все более плотного погружения массового сознания в сенсорное восприятие искусственно смоделированной реальности в рекламных роликах и видеоклипах, в повседневном засилии коммерческих и политических имиджевых пиартехнологий. Однако, бурный рост цифровых модификаций культуры - существенно опережает ее адекватное теоретическое осмысление.

Генезис развития понятия «цифровизация», показывает, что широкому распространению данного понятия в XX веке предшествовали, с одной стороны, интенсивное развитие информационных технологий XX века, с другой стороны, трансформации, произошедшие в концепциях понятия «виртуальность», 
существовавшие в философии и культуре начиная с античности. Понятие «виртуальный» исходит к латинскому термину «virtualis», который в свою очередь происходит от «virtus» - сила, душевный подъема воина, воинская доблесть. Однако в средневековье «virtus» стал обозначать некую таинственную силу, чье присутствие в объекте или в Боге не подлежало сомнению. Данная сила могла переводить объекты из небытия в бытие. В XIX в. под понятием «виртуальный» стало трактоваться все то возможное, что не соотносится с реальностью. В XX в. виртуальное уже стало рассматриваться, как то, что имеет свою собственную реальность, не являющуюся возможной и даже ей оппозиционной. Так, например, еще Анри Бергсон предлагал рассматривать «виртуальное» как то, что имеет «свое собственное существование» [БЕРГСОН, 2006]. То есть, в данной традиции виртуальное, которое стало рассматриваться как нечто, оппозиционное актуальному, реальному, действительному и стало синонимом возможного и потенциального. Таким образом, категориальный анализ термина «виртуальный» показал, что акцент в понимании данного слова, сместился от античного варианта толкования как «возможный», «потенциальный», «сила», «доблесть» к современному широкому употреблению в значении «ненастоящий», «мнимый», «кажущийся», «иллюзорный».

Теоретическое исследование феномена цифровой реальности охватывает целый ряд научных направлений, в том числе социально-философское, социологическое, культурологическое и другие, которые показывают место и значение феномена «цифровая реальность» в современной культуре. Даже этот небольшой анализ показывает, что сегодня понятие цифровой реальности трактуется в двух смыслах: 1) в узком (техническом) - как компьютерные системы, которые обеспечивают визуальные и звуковые эффекты, погружающие зрителя в воображаемый мир за экраном; 2) в широком (абстрактном) - как мнимый мир, создаваемый в воображении пользователя.

Понятие «цифровизации», особенно применительно к культуре, обозначает одновременно несколько, определяющих современную культуру, процессов. Если поставим концепт цифровизации в содержательно-временной контекст, ему безусловно предшествует процесс информатизации, а за ним, неизбежно следуют многоступенчатые стадии попыток создания искусственного интеллекта. Виртуализация - цифровизация - искусственный интеллект: неразрывная последовательность отчасти уже случившегося, и уже намеченного в качестве цели прогресса. Цифровизация уже внедрилась во все пласты повседневной, экономической и культурной жизни. Помимо безусловной пользы цифрового фиксирования, хранения, переработки и передачи информации, как и все новые явления, она генерирует и принципиальные вопросы, например относительно адекватной возможности оцифровования качественных составляющих субъективного или же художественного контента.

По поводу цифровизации существуют разные точки зрения. Например, понятие цифрового часто противопоставляется понятию реального. Цифровое здесь фигурирует как некое посягательство на истину, ценности и смыслы. 
Другое понимание связано с тем, что цифровизация это некая «вторая» реальность со своими персонажами, такими как роботы, клоны, боты и т.п. В данной статье мы предполагаем проанализировать эти цифровые виртуальности, в том числе их значение и социокультурные последствия.

Выбор методов, использованных в работе, обусловлен спецификой предмета и задачами, поставленными авторами статьи, которые обусловили комплексный междисциплинарный подход. Для раскрытия темы авторы обратились как к общенаучным методам: логическому анализу, абстрагированию, описательному методу, историко-генетическому, так и к непосредственно методам философии и социологии культуры.

\section{Изобразительное искусство в цифровом пространстве}

Изобразительное искусство относительно своей репрезентации прошло длинный путь от претензий быть пассивно созерцаемым до вовлечения воспринимающего субъекта в ткань самого творения. Художники могут быть услышаны и увидены за короткое время беспрепятственно в интернет-пространстве неограниченным числом людей. Цифровая вселенная, обходя все трудности репрезентации в реальном пространстве и времени, обеспечивает эту возможность. Цифровое искусство и искусство виртуальной реальности становится самой молодой и самой непредвиденной, подлежащей доскональному исследованию, сферой художественной самореализации. Вопрос: «Что же придет на смену цифровому и виртуальному искусству?» является таким же непостижимым, как и вопрос начала прошлого столетия: «Что придет на смену многовековому традиционному пониманию искусства?»

Благодаря технологическим прорывам, «пост-дюшановское искусство» распространилось на все жанры современного искусства. Цифровые технологии стали незаменимыми. Например, обработка фотографий, создала принципиально новые перспективы фотоискусства. Качественно изменили кинематограф как в плане его технических возможностей, так и тематического разнообразия сюжетов. Компьютерное искусство, интернет-искусство закономерным образом завоевали себе место под солнцем. В физическом арт-пространстве появились цифровые инсталляции трехмерных скульптур, созданных на сканерах. Мы можем привести еще много примеров цифровизации в области акустики и музыки, и богатую вариативность сочетания цифровых акустических и изобразительных техник.

Благодаря цифровизации, изобразительное искусство вышло за пространственные пределы галерей и выставочных залов, и скорее всего уже окончательно изменило классическое понимание музейной практики репрезентации предметов искусства: «...общение с искусством не ограничивается зрением и переходит к осязанию» - пишет Майкл Раш [РАш 2018: 242]. Зритель становится обязательным соавтором этого искусства, перестает быть пассивным воспринимателем, становится соавтором произведения.

Цифровое искусство, как новый логический этап технологического прогресса в искусстве, полностью порвало с притязаниями на материальность и «объектный статус» [РАШ 2018: 242] произведения. Вслед за радикальными 
изменениями способов репрезентации, утрачивают свою применимость понятия и критерии традиционной эстетики. Привязанность произведений к реальному времени, пространству или же образу и смыслу, диктованному художником, осталась в прошлом. Пришедший на смену новый контекст предполагает обязательное присутствие - уже даже и не зрителя, а скорее «соучастника» в самом творческом процессе. Обязательное присутствие зрителя как соучастника в процессе созидания основывается на определенной парадигме слияния автора со зрителем, обыденной жизни с искусством, окружающих нас повседневных предметов с арт-объектами, и тем самым осуществляет предполагаемую еще Жаном Бодрийяром развоплощение нашего мира: «Абстракция нашего мира уже давно стала повсеместным фактом, и все художественные формы безразличного мира несут в себе стигматы этого самого безразличия» [БОДРИЙЯР 2017]. Есть вероятность тому, что именно из-за «безразличного мира», описанного Бодрийяром: «люди будут обращаться к новому искусству в поисках опыта иного бытия〉 - пишет Майкл Раш.

Художник из Австралии Джеффри Шоу в своей работе «Правдоподобный город» еще в 1991-ом году средствами цифровой 3D анимации демонстрирует, какова может быть повседневная система цифровой реальности. Шоу установил велосипед перед тремя экранами, а зритель /соучастник/ крутя педали, проезжает по виртуальным улицам конкретного города, в данном случае Амстердама. В настоящее время эффект виртуальности создается более совершенными методами и создает почти неотличимую от действительности контекст пребывания в искусственно созданной реальности.

Остается сделать еще один технологический шаг, и он уже почти сделан, и виртуальность будет разворачиваться в реальном времени, а люди с детства, ориентирующиеся в виртуальном пространстве «...будут управлять ею с той же легкостью, с какой мы пользуемся дистанционным пультом или мобильным телефоном» [РАШ 2018]. Очевидно, что художниками движет интенция моделировать и тем самым предложить своему «соавтору» по возможности как можно больше свободы доведенной до ее пределов, до максимума. Росс Гибсон, австралийский медиакуратор и теоретик современного искусства в своем эссе, написанном в 2003-ем году описывает функцию художника, который «...будет производить не столько объекты, сколько опыт - он будет предлагать нам такой опыт, который будет глубоко «задевать» нас, погружая или выводя за пределы реально существующего мира» [GIBSON 2003].

\section{Массовая культура и цифровые технологии}

В сфере массовой культуры из-за прихода на арт-сцену новых зрелищных технологий производства формируется новый тип социальных практик, связанный с развитием индустрии интерактивных развлечений и услуг: ток-шоу, видеоролики, теле- и интернет-магазины, виртуальные ярмарки и аукционы, электронные тренажеры, интерактивные образовательные программы, лекции, семинары, мастер-классы и т.д. 
Результатом масштабной мутации стало становление глобальной массовой культуры с динамично развертывающейся зрелищной доминантой, основной стимул развития которой, провоцирование привычного человеческого восприятия чрезмерной интенсивностью и парадоксальностью предоставляемых зрелищных впечатлений. Все более интенсивный зрелищный шок от парадоксального сверхвидения, доставляемого либо необычностью ракурса съемки, либо запредельной панорамностью картины (природного бедствия, космического ландшафта и т.д.), либо самим видом искусственно смоделированных фантастических существ. Неудивительно, что самодовлеющее господство на экране ошеломляющих образов, произведенных с помощью компьютерной графики, специальных методов компьютерного монтажа (морфинга, компоузинга, захвата движения и т.д.), ведет, как справедливо отмечает Татьяна Савицкая [САВИЦКАЯ 2018], «К беспрецедентному обеднению текстовой и сценарной составляющих произведения, деградирующих, с одной стороны, до обмена шаблонными репликами; с другой, до фэнтезийно-комиксовых аморфных, распадающихся сюжетов. С точки зрения новоевропейской классики с ее литературоцентризмом, тягой к интроспекции и катарсису, такое коммерчески ориентированное, технологически фундированное массовое производство образов уже не является культурой; закономерно поэтому, что некоторые исследователи присваивают данному явлению наименование «пост-культуры», «пара-культуры» и т.д.».

Тяга к избыточной зрелищности, порождение посредством цифровых технологий все более совершенных оптико-кинетических иллюзий, т.е. тенденция цифровизации художественного процесса, - тренд, характерный как для массового искусства (блокбастеры, компьютерные игры, видеокомпьютерные шоу и аттракционы), так и для артхаусного искусства (видеоинсталляции, виртуальный театр, кинематографическая нонклассика), о чем мы писали выше. Закономерный шаг к голографической объемности изображения - стереокинематограф, как технология изобретенный еще в конце XIX века, но обретший культовую популярность после всемирного успеха в конце 2009 года фильма «Аватар», выполненного в 3D формате.

Безусловно, современная индустрия глобальной массовой культуры - кластер синхронно работающих информационных, развлекательных, коммуникативных, рекламно-коммерческих технологий, проявляет чудеса чуткости в отслеживании новых трендов «инфотейнмента» ${ }^{1}$, их маркетинговой раскрутке и освоении бизнесом, но инициатива в порождении таких трендов все же коренится в сфере общественной психологии. Это положение вполне оправдывается при анализе современного стереокинематографа. С одной стороны, коммерческий ажиотаж, последовавший за триумфальным успехом «Аватара», заставил обратиться к формату 3D известных режиссеров, таких как Роберт Земекис («Полярный экспресс», «Беовульф»), Роберт Родригез («Дети шпионов

1 Неологизм, сформированный из двух слов: information (англ. «информация») и entertainment (англ. «развлечение»), для обозначения «информационного развлечения», максимально комфортного с точки зрения технологических удобств досугового времяпрепровождения. 
3D - Игра закончена» и «Приключения Шакрбоя и Лавы»); крупные кинокомпании (вроде Диснея со стереомультфильмом «Цыпленок Цыпа»). Для координации усилий бизнес-кругов в производстве высокотехнологичной 3D-продукции был создан даже специальный 3D консорциум; оснащение сети новых кинотеатров аппаратурой, необходимой для трансляции фильмов в формате $3 \mathrm{D}$, уже привело к росту стоимости билетов в них на 20-40\% [САВИЦКАЯ 2018].

Парадоксальный характер цифровизации массовой культуры на современном этапе технической революции приводит ряд исследователей к выводу, что «на смену культуре идет виртуальность дигитальных сетей, фантом технической цивилизации новейшей электронной эры, которая требует от человека кардинального изменения всего его существа, чтобы быть аутентичным ей»; новой эпохе соответствует «новый антропный вид, антропоид, не исторический человек, которому культура не нужна» [Бычков 2009:183].

На наш взгляд, можно говорить о массированной цифровизации массовой культуры, которая прочно утвердилась в роли главного тренда развития постсовременной культуры. Подтверждением нашему выводу является тот факт, что негласным каноном кино - и медиаэстетики давно уже стала опора на масштабное производство виртуальных артефактов от спецэффектов в блокбастерах, моделирования реальности в ширящейся империи онлайновых интерактивных видеоигр, гиперреальной трансформации изображаемых объектов в рекламных роликах и видеоклипах до погружения в сконструированную автореальность видеоинсталляций и видеоарта в авангардных проектах «актуального искусства».

И еще об одном инструменте массовой культуры - телевидении. В «экранной культуре», как иногда определяют исследователи, современное общество, человек получает искаженную экраном информацию о мире, и дело не в том, что любой образ не тождественен объекту, который он представляет, а в том, что образы сегодня стали более реальны, чем сама реальность и претендуют на истину, захватывают власть над ней, подменяют саму реальность. Тема цифровизации культуры и влияния новых технологий на мышление и поведение человека поднимается в романе Рэя Брэдбери «451 градус по Фаренгейту»: «Вы можете закрыть книгу и сказать ей: «Подожд». Вы ее властелин. Но кто вырвет вас из цепких когтей, которые захватывают вас в плен, когда вы включаете телевизионную гостиную? Она мнет вас, как глину, и формирует вас по своему желанию. Это тоже "среда" - такая же реальная, как мир. Она становится истиной, она есть истина» [БРЭДБЕРИ 2015]. Таким образом, телевидение и другие медиа, ориентированные на визуальный способ передачи информации, играют большую роль в создании альтернативных миров, искусственных пустых форм, ложных образов.

\section{Цифровая реальность}

Создание цифровой реальности, осмысленной в качестве симуляционной реальности, стало предметом исследования теоретиков постмодернизма, прежде всего, Ж. Бодрийяра в его фундаментальной работе «Симулякры и симуляция» («Simulacres et simulation») [БОДРийяР 2016]. Ж. Бодрийяр говорит, 
что «в наши дни виртуальное решительно берет верх над актуальным; наш удел - довольствоваться такой предельной виртуальностью, которая лишь устрашает перспективой перехода к действию» [БОДРИйяР 2016]. Структурной единицей, доминирующей в современной культуре, по мнению Ж. Бодрийяра, становится «симулякр», т.е. псевдовещь, замещающая "агонизирующую реальность” посредством симуляции. Как следствие, с воцарением искусственности исчезает различие между реальным и нереальным, аутентичным и неаутентичным, между истинным и ложным. И современная культура, таким образом, предстаёт в качестве своеобразной виртуальной системы, где подлинная социокультурная реальность подменяется симуляционной - гиперреальностью. Бодрийяр показал, что следствием процесса разложения информации становится утрата потребности в ее получении и, наоборот, усиление зависимости от технических средств, способных замещать реальность ее подобиями. По существу, в «современном обществе средства массовой коммуникации и функционируют как системы, создающие множественные инварианты, альтернативные константной реальности, где смысл сообщения нейтрализуется и разрушается, где реальность заменяется симулятивными ее знаками, составляющими гиперреальность» [БОДРИйяР 2016]. В итоге - обратно пропорциональная зависимость между увеличением информации и возрастанием смысла. Причину этих процессов, к примеру, Ж. Бодрийар усматривает в «абсолютной несоотнесенности информации и сигнификации, где сфера информации предстает как чисто техническое средство, подобное коду. Реальность, дублированная посредством репродуктивных материалов, улетучивается, «становится аллегорией смерти, но самим этим разрушением она и укрепляется, превращается в реальность для реальности...: гиперреальность»» [БОДРИЙяР 2016].

Ж. Бодрийяр задается вопросом: «Может ли эта дедраматизированная симуляция продолжаться до бесконечности? Каковы бы не были формы, с которыми мы имеем дело, мы давно уже пребываем в приходраме исчезновения и транспарентности» [БодРИЙЯР 2016] Это состояние ничто иное, как упразднение человеческой свободы заменив ее свободой воображения, о котором сам человек и не ведует. Помещение человека в виртуальную реальность снимает изначальную философскую проблему свободы человека, так как действие человека больше не будет иметь не только моральных критериев, но и реальных последствий своих виртуальных выборов. Человек растворяется и исчезает в искусственном мире без малейшей возможности возвращения в деятельную сферу Homo sapiens. Становится необходимым философское осмысление новой реальности в искусстве, ведь радикальная ломка прежней арт-парадигмы напрямую затрагивает лежащие в основе онтологические вопросы.

Рефлексия на вышеперечисленные явления со стороны эстетических теорий, не оставляют себя ждать. Одной из самых примечательных эстетических конструкций постмодерна является т.н. алгоритмическая эстетика, которая своим оценочным инструментарием является самой адекватной по отношению своего объекта. [МАНЬКОВСКАЯ 1994; МиГУНОВ-ЕРОХИН 2010; STINY-GIPS 
1988]. Постмодернистская эстетика отличается многообразием правил языковых игр, их машинностью и экспериментальностью, причем правила эстетических игр меняются под воздействием компьютерной техники. Параллельно тому, как обсуждаются проблемы специфики интеллектуальной красоты, роли эстетических суждений и художественных образов в науке, наблюдается и зеркальный процесс внедрения в эстетику математизированных и компьютерных анализирующих моделей, функцией которых является в принципе количественными способами давать оценку эстетическому содержанию художественных произведений. Целью алгоритмической эстетики стало не только осмысление с эстетической точки зрения художественной практики, связанной с развитием компьютерной графики, музыки, видеоклипов, рассматриваемых как художественных произведений, но и выработка новых теоретических подходов, сочетающих философские и математические принципы исследования культуры, способные делать выводы об алгоритмах творчества искусства.

Применяемый алгоритмический принцип ассоциируется с применением методов математического программирования в описании, интерпретации и эстетической оценки произведений искусства, с созданием компьютерных моделей творчества и художественной критики. Сущность метода состоит в абстрагировании на основе непосредственного эстетического опыта произвольных исходных данных, результатом которого получаем полностью определяемые этими данными результаты. При этом каждый последующий шаг процесса задан рамками непосредственно ему предшествующим. Не зависимо от того, какова конкретная частная задача - описание, интерпретация или же оценка эстетических объектов - заданным алгоритмом процесс представлен черным ящиком, а изучаемая совокупность данных, это информация чаще всего представляемая в виде знаков на входе и выходе. Эстетическая ценность художественного произведения в алгоритмической эстетике измеряется разницей объемов информации на выходе и на входе: чем больше прироста информации на выходе, тем выше эстетическая ценность рассматриваемого и принадлежащего оценке объекта искусства. Принцип количественной максимизации переживаний, вызванных художественным произведением, предполагает неглигацию качественного аспекта переживания, то есть стирается разница между позитивными и негативными эмоциями.

Искусство создавало всегда виртуальность, но виртуальность реального внутреннего и внешнего мира человека отображая сущность состояния мира или же человеческих переживаний. В настоящее время искусство - элиминируя из сферы своих объектов реального человека с его реальным окружением - создает безотносительную к реальности виртуальность, которая «забегая вперед» предвосхищает реализацию одной из наметившихся альтернатив будущего: смену онтологического статуса мировосприятия человека. Элиминация из мировосприятия и миропонимания человеком сложнейшей и бескомпромиссной реальности сулит потерей над ней власти и контроля и как последствие - предчувствие полного бессилия и потерянности индивида, о чем 
неустанно и твердит нам искусство постмодерна. Таким образом, напрашивается вывод, согласно которому искусство само способствует созданию реальности, но уже не реальности искусства, а реальности виртуальности. Естественным образом напрашивается вопрос, что станет с культурой, историей, что останется в коллективной памяти человечества и в индивидуальной памяти отдельного человека, если «настоящие» переживания мы не сможем отличить от искусственных? Как на этот вопрос отвечает Майкл Раш? «Жизнь, какой мы ее знали, в том числе воспоминания, которые нам от нее остаются, навсегда изменится, когда «виртуальное» и «реальное» станут неразличимы. Быть может, воспоминания сольются с фантазиями» [РАШ 2018] - пишет исследователь.

Парадокс онтологического статуса цифровой реальности ставит человека перед цивилизационным выбором: или идти дальше по этому непредсказуемому пути - может к искусственному интеллекту, или же искать более предсказуемые альтернативы выживания человека и культуры.

На наш взгляд, нельзя не сказать, еще об одном из ярчайших современных культурных трендов - массированном внедрении в социум разнообразных программ и проектов, основанных на технологии дополненной реальности (англ. augmented reality, AR), безграничность сфер применения которых (от рекламы, маркетинга, туризма, музеев, выставок, журнального бизнеса, компьютерных игр до медицины и педагогики) и транслируемое ими расширение возможностей восприятия заставляют адептов модной новации говорить о приближении нового качественного скачка в развитии современной цивилизации, соизмеримого с открытием Интернета. Строго говоря, дополненная реальность называется так по причине добавления к поступающим из реального мира восприятиям неких мнимых (виртуальных) объектов, как правило, информативно-вспомогательного характера. Еще в конце 90-х гг. Рональд Азума (Ronald Azuma) определил дополненную реальность как систему, «которая: 1. Совмещает реальное и виртуальное; 2. Обеспечивает взаимодействие пользователя и машинного интерфейса в реальном времени; 3. Работает в 3D» (AZUMA 1997: 355-385).

«Дополненная реальность в России, да и во всем мире, - пишет Анастасия Черникова, обозреватель чуткого к технологическим новациям сайта Look at $\mathrm{me}^{2}$, - находится в стадии ожидания - дальше ей на смену придет уже другая, виртуальная реальность, а реальный мир будет неотделим от цифрового. ... Сейчас же мы находимся в начале поля экспериментов. Вопросов больше, чем ответов, и утверждать можно только одно - дополненная реальность в том или ином виде никуда не денется и, скорее всего, перерастет во что-то большее. Эта технология будет проникать в жизнь людей, как в свое время это сделали социальные сети» [ЧЕРниковА 2014] Аналитик специального сайта Arnext, по-

2 Cайт Look at me (LAM) основан А. Аметовым и В. Эсмановым в 2006 гожу как электронное СМИ; представляет собой ежедневное интернет-издание с собственной социальной сетью. По данным Google Analytics, в феврале 2011 года месячная аудитория сайта составляла 1 млн. человек, а в мае 2012 года - уже 2,5 млн. 
священного дополненной реальности, констатирует: «Работы над новыми типами естественных интерфейсов, путь к которым проходит виртуализацию данных физического мира, полным ходом идут в Google, Apple и Microsoft, с дополненной реальностью экспериментируют в Samsung и Intel, Epson и IBM, Xerox и Hewlett Packard, в AR-потоке открываются десятки стартапов, имеющих передовые идеи использования аппаратных платформ. Будущее наступило, будущее наступает» [Лиссвицкий 2014].

Дополненная реальность как перспективная и многообещающая технология, совмещающая в реальном времени объекты реального и виртуального миров, в условиях несовершенного человеческого общества способна превратиться в зону повышенного риска, чреватую новыми неожиданными угрозами. Как отмечают в статье «Преступные, зловредные и неожиданные области применения дополненной реальности», выложенной на сайте Help Net Security, Грегори Конти, Эдвард Собиск, Стивен Биллингтон и Кори Кирк, «эра повсеместного использования дополненной реальности стремительно приближается и вместе с ней - удивительные возможности и беспрецедентный риск» [КУзин 2012].

\section{Заключение}

Проведя анализ фундаментальных идей о сущности процесса цифровизации современной культуры, мы пришли к выводу, что она представляет собой процесс отображения информации, при котором у пользователя возникает ощущение пребывания в мире, синтезированном, в свою очередь, определенными устройствами. Культура в цифровой реальности включает в себя производство высококачественных средств стереоизображений, создание устройств воздействия на другие (помимо зрения) каналы поступления информации в человеческий мозг при соответствующих обратных связях и разработку программного обеспечения, позволяющего формировать необходимые образы в реальном масштабе времени.

При этом свойством цифровизации современной культуры обладает любая субъективная реальность. Последствиями цифровизации культуры, будет развитие механизмов глобального культурного обмен, так как новые медиа, обладая трансграничностью, дают возможность преодолеть языковые и культурные барьеры.

В современной культуре глокализация, отчетливо проявляется в виде «ослабления связи между культурным феноменом и его географическим местоположением, приближения к нам далеких событий, влияний и опыта». По мнению Э. Гидденса, в современных условиях происходит «пространственно-временное дистанцирование транслируемых форм культуры от их изначального контекста».

С развитием сети «Интернет», кабельного и интернет-телевидения с большим количеством каналов начался процесс размывания массовой культуры ввиду появления у потребителя широких альтернатив по выбору информации.

Но наряду с позитивными аспектами цифровизации культуры, необходимо помнить о возможности существования отчужденной от человека, объективированной цифровой реальности в виде общих образов, представлений, символов и 
т.п. («символический универсум» в определениях социологов П. Бергера и Т. Лукмана). По мнению М. Кастельса, «исторически специфичным в новой коммуникационной системе, организованной вокруг электронной интеграции всех видов коммуникации, от типографского до мультисенсорного является не формирование виртуальной реальности, а строительство реальной виртуальности».

Завершить нашу статью еще одним выводом. В финале романа Умберто Эко «Имя розы» вместе с монастырской библиотекой сгорает бесценная рукопись второй части аристотелевской «Поэтики», существовавшая в единственном экземпляре и невосстановимая. Конечно, факт существования этой рукописи, как и смутные слухи о ее кощунственном для христианской культуры содержании были выдуманы итальянским философом и писателем. Но тема пропавших, утраченных, уничтоженных книг - одна из самых трагических в мировой культуре.

Булгаковское знаменитое «рукописи не горят» становится абсолютно реальным для современной культуры, ставшей цифровой и постоянно воспроизводящей, дублирующей себя в бумажном, электронном, цифровом виде. Главное - не забывать делать бэкапы [ЛЕвЧЕНКо].

\section{Библиография}

БЕРГСОН 2006: Бергсон, А. Творческая эволюция. Москва: Академический проект.

БодРийяр 2016: Бодрийяр, Жан, Симулякры и симуляции. Simulacra et simulation. Москва: Постум.

БРЕДБЕРИ 2015: Брэдбери, Рэй, 451 градус по Фаренгейту. Санкт-Петербург: Каро.

Бычков 2009: Бычков, В.В. Триалог. Разговор второй о философии искусства в разных измерениях. - Бычков В.В., Маньковская Н.Б., Иванов В.В. - Москва: ИФРАН.

Кузин 2012: Кузин, А. Технологии информационных войн недалекого будущего: дополненная реальностью. Режим доступа:

https://al-kuzin.livejournal.com/289853.html (дата обращения: 22.11.2019)

ЛЕВченКО: Левченко, М. Рукописи горят, или Виртуализация культуры. http://www.ruthenia.ru/60s/articles/scanirovanie.html (дата обращения: 20.07.2019).

Лиссвицкий 2014: Лиссвицкий, А. Дополненная реальность: итоги 2013 года по версии ARnext [Электронный ресурс]. - Режим доступа: http://www.arnext.ru/articles (дата обращения: 22.08.2019)

МАНЬКОВСКАЯ 1994: Маньковская, Н.Б. Париж со змеями. Москва. Российская Академия Наук. Институт философии.

Мигунов-ЕРохин 2010: Мигунов, А.С., Ерохин, С.В. Алгоритмическая эстетика. Санкт-Петербург: Алетейя.

РАш 2018: Раш, Майкл, Новые медия в искусстве. Ад Маргинем Пресс. Москва.

САВИЦКАЯ 2018: Савицкая, Т. Блеск и нищета цифры. ИНТЕРЛОС. Интеллектуальная Россия http://www.intelros.ru/subject/figures/tatyana-savickaya/23648-dopolnennayarealnost.html

ТАНАТОВА 2019: Танатова, Д.К. Цифровое VS Традиционное общество: преимущества и риски / В сборнике: Россия в эпоху цифрового общества: границы, барьеры и 
солидарности Материалы XXIV Социологических чтений РГСУ. Российский государственный социальный университет, Редколлегия: Т.Н. Юдина, И.В. Долгорукова, И.В. Королев, Т.В. Фомичева, Е.А. Лидзер. 2019. 10-23.

ЧЕРникОВА 2014: Черникова, А. Дополненная реальность: три перспективы [Электронный ресурс]. - Режим доступа: http://www.lookatme.ru/mag/industry/industryresearch/193763 (дата обращения: 24.08.2019).

ЮдинА 2019: Юдина, Т.Н. Мигрантские сообщества: от реальных социальных связей к виртуальным социальным сетям // Россия в эпоху цифрового общества: границы, барьеры и солидарности Материалы XXIV Социологических чтений РГСУ. Российский государственный социальный университет, Редколлегия: Юдина Т.Н., Долгорукова И.В., Королев И.В., Фомичева Т.В., Лидзер Е.А. 64-73.

AzUma 1997: Azuma, Ronald T. A Survey of Augmented Reality. Presence: Teleoperators and Virtual Environments 6.

GIBSON 2003: Gibson, R. The Time Will Come When ... In Jeffrey Shaw, Peter Weibel (Eds.), Future Cinema: the cinematic imaginary after film, Cambridge, MA: MIT Press.

STINY-GIPS 1988: Stiny, G., Gips, J. Algorithmic Aesthetics. Computer Models for Criticism and Design in the Arts. 2 ed. Berkely.

Дебреценский университет

Дебрецен, Венгрия

szucs.olga@arts.unideb.hu

Дина ТАНАТОВА

Российский государственный социальный университет

Москва, Россия

dktanatova@mail.ru

Татьяна ЮдинА

Российский государственный социальный университет

Москва, Россия

ioudinatn@mail.ru 